\title{
COMPOSITION AND SENSORY ASSESSMENT OF PIZZA MADE FROM WHEAT (TRITICUM AESTIVUM), YELLOW MAIZE (ZEA MAYS), AND COWPEA (VIGNA UNGUICULATA) FLOUR
}

\author{
Mary Adusei ${ }^{1}$, Nanice Fosu ${ }^{2}$, Veronica Akwaah ${ }^{2}$ \\ ${ }^{1}$ St. Louis College of Education, P. O. Box 3041, Kumasi, Ghana. \\ ${ }^{2}$ St. Ambrose College of Education, Voc/Tech department, Box 25, Wamfie-Ghana \\ ${ }^{2}$ St Monica's college of Education, Box 250, Mampong Ashanti, Ghana
}

Corresponding Author: Veronica Akwaah

Article DOI: https://doi.org/10.36713/epra9590

DOI No: 10.36713/epra9590

\begin{abstract}
The purpose of the study was to determine the proximate composition and acceptability of prepared pizza made with wheat, maize, and cowpea flour blends. Five types of pizza were made with wheat flour, maize flour, and cowpea flour as the main ingredients. The proximate and sensory properties of pizza samples were made with varied formulas, such as 100:0:0, 90:6:4, 80:13:7, 70:18:12, and 60:25:15\%. As a control, a pizza made entirely of wheat flour was used. The protein content of wheat and composite flour pizza samples ranged from 12.14 to $12.92 \%$, moisture from 12.59 to $12.82 \%$, ash from $1.56-2.31 \%$, crude fat from 1.22-1.48\%, crude fiber from 0.77 to $0.43 \%$, and carbohydrate from 53.2 to $53.44 \%$. The protein content of the pizza samples varied greatly $(P<0.05)$, with pizza made from $60 \%$ wheat flour, $25 \%$ maize flour, and $15 \%$ cowpea flour having the highest protein content and pizza made from wheat flour having the lowest protein content. A panel of twenty panelists was used to assess the sensory qualities such as colour, taste, texture, aroma, and overall acceptability of pizza samples using a 5point structured hedonic scale. The pizza sample made with $80 \%$ wheat flour, $13 \%$ maize flour, and $7 \%$ cowpea flour received higher ratings than the control sample, but all of the pizza samples associated well with the control in all of the criteria examined. It was found that up to $13 \%$ and $7 \%$ yellow maize and cowpea can be included in wheat in pastry and dough preparations without affecting the nutritional composition or sensory qualities.
\end{abstract}

KEYWORDS: Pizza, Yellow corn, cowpea, local materials, dough, flour cookery, nutritional profile.

\section{INTRODUCTION}

Pizza is a popular and common fast food item with a high-calorie content that can be made with simple and readily available ingredients such as wheat flour, oil, salt, and yeast. It is classified as one of the world's most widely baked products and can be defined as flatbread leavened with raising agent or yeast and topped with tomato sauce and often cheese, with other toppings (Redl et al. 2003). Food manufacturers are paying greater attention to the development of high-quality pizza dough, which is influenced more by the leavening process than by the characteristics of the raw materials or the method of preparation. Wheat flour is one of the most important ingredients to consider when it comes to flour cookery (Lehman 1997; Andrea and Aniello 2003). Wheat flour is known to be more expensive in Ghana than other cereals because it is not produced locally. However, there are many other crops grown in Ghana and many researchers have attempted to supplement wheat flours with non-wheat flours, particularly legume and other cereal flours for pastry and dough products (Okaka and Isieh, 1990; Onweluzo et al., 1995).

Maize (Zea mays) is one of the world's most significant cereal grains used as a staple food for about 400 million people in underdeveloped nations. It is used as a food ingredient and animal feed (Odebode et al., 2008). Developing 
countries such as Nigeria, Ghana, and Africa contribute around half of the world's maize production, which is projected to be 603 million tons (Samapundo et al., 2007). Maize is a key energy source with 86 calories per 100 grams and it is high in B vitamins, thiamine, pantothenic acid (BS), and folate. They are high in dietary fiber, minerals, and phosphorus (Rooney \& Serna-Saldvar, 2000). Maize flour is one of the most frequent forms of maize that is used to make banku, kenkey, bread, biscuits, doughnuts, pudding, and several other dishes. The grain comprises $65-84 \%$ carbohydrate, $9-10 \%$ protein, $12-15 \%$ moisture, $3-5 \%$ fat, $2-3 \%$ fiber, $3 \%$ ash, and 410 calories, according to Onyemaobi et al., (2005). Maize is lower in nutrient value than wheat, and it lacks niacin. The yellow maize flour was chosen for this study because it contains a lot of beta-carotene, a provitamin that helps humankind to see well.

The cowpea (Vigna unguiculata L. Walp.), is a member of the Papilonacaeae (Fabaceae or Leguminosae) family that originated in Sub-Saharan Africa (Brink \& Belay, 2006). Cowpea is a popular pulse/starchy legume crop in Sub-Saharan Africa, with Asia and the Americas as additional consumption locations. Cowpea is a nutrient-dense food that is high in protein (24\%) dietary fiber (11\%), and potassium $(1112 \mathrm{mg} / 100 \mathrm{~g})$, but low in fats (2\%) and salt $(16 \mathrm{mg} / 100 \mathrm{~g})$ (USDA, 2021). Except for cysteine and methionine, cowpea protein contains significant levels of essential amino acids. It is one of the richest and most affordable sources of plant protein used to improve the diets of the poor and low-income, notably in both developed and developing countries (Enwere, 1998). It can be made into paste, flour, protein isolates, and concentrates, all of which can be used to make a variety of foods (Okaka and Potter, 1979; Ngoddy et al., 1986; Enwere and Ebiogwu, 1993). The nutritional composition, taste, cost, and availability of beans all influence its consumption in Ghana and other parts of West Africa. The formation of interesting processed maize, cowpea, and wheat flour composite products will thus play a key role in expanding awareness of the crops potential. Many researchers have experimented with making composite flours from various crops for confectionery and bakery goods, including cassava/wheat flour (Shittu et al., 2013), wheat/taro flour (Ammar et al., 2009), wheat/pumpkin flour (Shittu et al., 2008), and tiger-nut/wheat flour (Ade-Omowaye et al., 2008). However, there is very little information available on maize/cowpea/wheat composite flour for pizza. According to Khan (2005), composite flour technology has numerous benefits, including the ability to supplement important vitamin deficiencies. It conserves hard cash, promotes high-yielding local plant varieties, and improves domestic agriculture's overall use. Ghana has good terrain for the development of a variety of grain and pulses. The worldwide focus is turning away from over-reliance on imported items and toward locally produced goods. The idea of combining maize and cowpea for the preparation of home food products is attracting a lot of interest around the world (Nnam, 2002). To combat protein-energy malnutrition (PEM) and micronutrient deficiencies, these items would be reasonably inexpensive, nutritious, and accessible to the poor. As a result, the study aims to produce an acceptable pizza from yellow maize, cowpea, and wheat composite flours which will ensure food security, and expand farming and economic activity on the African continent.

\section{MATERIALS AND METHODS}

\section{Source of Raw Materials}

Wheat flour, yellow maize, cowpea, salt, oil and yeast were purchased from a local market in Kumasi Central market, Ghana.

\section{Preparation of samples Maize flour}

Cleaned, separated/sorted maize seeds were rinsed and steeped overnight. Before grinding, the wet cereal was rewashed and sundried for two days. The seeds were hammer crushed into flour and placed in a plastic bag with a $40 \mathrm{~mm}$ mesh screen.

\section{Cowpea flour}

The cowpea flour was made using the method given by Okaka (1997) but with a few changes. Cowpea seeds were weighed, washed, and soaked for 20 minutes in clean portable water. The seeds were then drained, dehulled by hand, boiled (at $100^{\circ} \mathrm{C}$ for 20 minutes), and dried in a $65^{\circ} \mathrm{C}$ oven for 6 hours. Milled, sieved, and packaged in plastic bags until analysis.

\section{Preparation of composite flour blends}

The composite flour was prepared by mixing wheat flour, maize flour and cowpea flour in a percentage of MK0 (100\% wheat, $0 \%$ maize flour and $0 \%$ cowpea flour), MK1 (90\% wheat flour, $6 \%$ maize flour and $4 \%$ cowpea flour), MK2 (80\% wheat flour, 13\% maize flour and 7\% cowpea flour), MK3 (70\% wheat flour, 18\% maize flour 
and $12 \%$ cowpea flour) and MK4 (60\% wheat flour, 25\% maize flour and 15\% cowpea flour). The flours were homogeneously mixed using a B8 universal mixer (IPX1, 7076) at $550 \mathrm{rpm}$ for 150 minutes. The resulting blends were packaged in polyethylene bags and used immediately in pizza production. Pizza sample MK0 containing $100 \%$ wheat flour was used as a control. In all, five (5) sample flours were formulated and used in the preparation of the various pizza products.

\section{Pizza preparation}

In order to make pizza, Kent (1984)'s methods were used with some modifications. The yeast was first dehydrated in heated $\left(40^{\circ} \mathrm{C}\right)$ water $(8 \mathrm{ml}$ water/g yeast $)$ and then allowed to ferment for 10 minutes. To make dough, all of the ingredients (Table 1) were mechanically mixed in a mixer for around 10-15 minutes. The dough was prepared and laid aside for 1 hour. To prevent moisture loss during fermentation, the dough was covered with a damp cloth. After 1 hour, the dough was knocked-back to drive out the gas that had formed, resulting in a more thorough mixing and evening of the temperature. The dough was allowed to rest for another 40 minutes after manipulation, during which it was re-kneaded to tighten it so that the gas was better dispersed and maintained. It was then divided into $200 \mathrm{~g}$ loaf-size sections and flattened roughly. The dough pieces were rested at $27^{\circ} \mathrm{C}$ for $10-15$ minutes, shaped ( 0.25 inch thick), and placed in pre-greased baking pans. The dough was rested in the baking pan for 30 Minutes at $37^{\circ} \mathrm{C}$, after which, topped with cheese and fried chicken breasts, and baked for 20 minutes at $210^{\circ} \mathrm{F}$. Dressing components included tomato ketchup and sliced cucumber on the pizza. The same approach was used to prepare the composite pizza samples.

Table 1: Formulation of ingredients for pizza preparation

\begin{tabular}{lccccc}
\hline INGREDIENTS & MKO & MK1 & MK2 & MK3 & MK4 \\
\hline Soft wheat flour $(\mathrm{g})$ & 100 & 90 & 80 & 70 & 40 \\
Maize flour $(\mathrm{g})$ & 0 & 6 & 12 & 17 & 35 \\
Cowpea $(\mathrm{g})$ & 0 & 4 & 8 & 13 & 25 \\
Vegetable oil (mL) & 6 & 6 & 6 & 6 & 6 \\
Yeast(g) & 10 & 10 & 10 & 10 & 10 \\
Salt(g) & 1 & 1 & 1 & 1 & 1 \\
Water (mL) & 150 & 150 & 150 & 150 & 150 \\
Topping and dressing Materials & & & & \\
Fried chicken breast & 100 & 100 & 100 & 100 & 100 \\
Cheese (g) & 20 & 20 & 20 & 20 & 20 \\
Tomato ketchup (mL) & 10 & 10 & 10 & 10 & 10 \\
Cucumber & 20 & 20 & 20 & 20 & 20 \\
\hline
\end{tabular}

Pizza samples: MK0 (100\% wheat flour, 0\% maize flour and 0\% cowpea flour), MK1 (90\% wheat flour, $6 \%$ maize flour and 4\% cowpea flour), MK2 (80\% wheat flour, 13\% maize flour and 7\% cowpea flour), MK3 (70\% wheat flour, $18 \%$ maize flour and 12\% cowpea flour) and MK4 (60\% wheat flour, $25 \%$ maize flour and $15 \%$ cowpea flour).

Proximate composition of the various pizza samples produced

Proximate composition (moisture, protein, fat, fibre, ash and carbohydrate contents) of the wheat and composite pizza samples were determined using methods described by AOAC, (1990).

\section{Moisture Content}

AOAC (2005) proposed a method for determining moisture content using a hot air oven. Two grams ( $2 \mathrm{~g})$ of the material was put into an empty crucible, which was weighed. This was placed in a hot air oven and dried at $100^{\circ} \mathrm{C}$ for 24 hours. In the desiccator, the crucible and its contents were cooled, and their weights were taken. The weight loss was referred to as moisture content and was represented as;

$\% 100$ moisture content $=\underline{\text { weight loss moisture }} \times 100$

Ash Content

weight of sample

Ash content was assessed using the method of AOAC (2005). (2005). Five grams (5g) of each sample was weighed into crucibles in duplicate, then burned at $550^{\circ} \mathrm{C}$ in a muffle furnace until a light grey ash was detected and 
a steady weight was obtained. To avoid moisture absorption, the sample was cooled in a desiccator and weighed to determine the ash content.

$$
\text { Ash }(\%)=\frac{\text { weight of ash x100 }}{\text { weight of sample }}
$$

\section{Crude protein determination}

The standard Kjeldahl (AOAC, 1990) method was used to determine this. Weighing $5 \mathrm{~g}$ of flour samples and placing them in a digestion flask. This was monitored by the adding $0.7 \mathrm{~g}$ of mercuric oxide, $15 \mathrm{~g}$ sodium sulphate, anti-bumping granules, and $25 \mathrm{ml}$ of concentrated sulphuric acid. The flask was angled at 450 degrees on the digesting rack. After the frothing stopped, the temperature was raised and the samples were boiled for about 2 hours, or until the solution was clear and colorless. After cooling the flask and its contents, $200 \mathrm{ml}$ of distilled water was added, along with $0.5 \mathrm{~g}$ of zinc granules to prevent bumping. A burette was used to correctly pour $50 \mathrm{~mL}$ of standard acid and $100 \mathrm{~mL}$ of distilled water into the distillate receiving flask, along with a few drops of the indicator. To make the solution extremely alkaline, the sample in the flask was chilled and $90 \mathrm{ml}$ of the sulphide -sodium hydroxide mixture was added. The Kjeldahl flask was then connected to the distillation rack's bulb, and heat was supplied to collect at least 150-200 ml of the distillate. After then, a standard $\mathrm{NaOH}$ solution was used to titrate the receiving flask $(0.1 \mathrm{~N})$. According to the AOAC (1990), the protein \%age was calculated.

$\%$ Protein $=\underline{0.00014 \times(\mathrm{T}-\mathrm{B}) \times \mathrm{N} \times \mathrm{Vt} \times 100 \times 6.25}$

$$
\text { Vax W }
$$

$\mathrm{T}=$ Titre value for sample

$\mathrm{B}=$ Titre value for blank

$\mathrm{N}=$ Normality of $\mathrm{HCl}$

$\mathrm{Vt}=$ Total digest volume

$\mathrm{Va}=$ Volume of aliquot

$\mathrm{W}=$ Weight of sample

\section{Crude fat determination}

A $250 \mathrm{~mL}$ soxhlet flask was rinsed and dried in the oven for 3 minutes at $105^{\circ} \mathrm{C}$. The flask was weighed after cooling in the desiccator. The flour samples were then weighed into a filter paper and neatly packaged. After that, it was carefully transferred into the thimble, which was then inserted into the extracting unit. The weighing dish was soaked in a solvent before being put into the thimble and plugged with defatted cotton wool. The solvent was added to the cleaned soxhlet flask containing anti-bumping granules to fill about two-thirds of the flask's volume, and the flask was equipped with the soxhlet extraction device. The fat was then extracted continuously from the samples for 3-5 hours, with the solvent condensing at 5-6 drops in the soxhlet extraction machine. Petroleum ether was distilled from the flask using a thermo-regulated hot water bath once the extraction was complete. The flask was dried in an oven at $100 \mathrm{oC}$ for 5 minutes after the petroleum ether vapour had been fully evaporated, then cooled in a desiccator and weighed. On a \%age basis, the difference in weight was determined as crude fat content.

\section{Total dietary fibre content}

In a $50 \mathrm{ml}$ centrifuge tube, one gram of sample was weighed, $2 \mathrm{ml}$ dimethyl sulphoxide was added, and the tube was closed. To homogenize the mixture, it was agitated on a magnetic stirrer for about 2 minutes before being placed in a beaker of boiling water on a hot plate with stirring. After 1 hour of mixing, the tube was removed without cooling, and $8 \mathrm{ml}$ of sodium acetate buffer at $\mathrm{pH} 5.2$ was added, pre-equilibrated at 50oC, and vortex mixed. The tube was kept at room temperature, around $35^{\circ} \mathrm{C}$, until the contents reached a temperature of $30^{\circ} \mathrm{C}$ to $40^{\circ} \mathrm{C}$. Vortex combines $0.5 \mathrm{ml}$ alpha-amylase solution, $0.1 \mathrm{ml}$ pullulanase solution, and $0.5 \mathrm{ml}$ alpha-amylase solution. For the first 1 hour, the tube was capped and incubated overnight with constant mixing. $40 \mathrm{~mL}$ ethanol was added, mixed thoroughly by inversion, and kept at room temperature for 1 hour. The mixture was then centrifuged for 10 minutes at $1500 \mathrm{~g}$ before decanting as much of the supernatant as feasible without disturbing the residue. The residue was then washed twice with $50 \mathrm{~mL} 85 \%$ ethanol each time, and the residue was suspended by inversion on a magnetic stirrer, with the supernatant removed as before. To wash the residue, $40 \mathrm{~mL}$ acetone was added, agitated for 5 minutes, and then centrifuged at $1500 \mathrm{~g}$ for 10 minutes. The supernatant liquid was removed by discarding it and immersing a tube in a beaker of water heated to $650^{\circ} \mathrm{C}-750^{\circ} \mathrm{C}$ on a stirrer hot plate with continuous stirring of the contents to mix until the residue appeared dry (Englyst, 1997).

$\%$ total dietary fibre is calculated using the formula: Weight of residue/weight of sample $\mathrm{x} 100$ 


\section{Carbohydrate content}

The carbohydrate content of the flours was calculated using AOAC guidelines (1990): \% carbohydrate $=100-$ $(\%$ fat $+\%$ protein $+\%$ ash $+\%$ dietary fibre $+\%$ moisture $)$.

\section{Sensory Evaluation}

A panel of 20 judges used a 5-point structured hedonic scale to assess the sensory qualities of colour, taste, texture, aroma, and overall acceptability of pizza composite samples and the control (100\% Wheat flour). The grading system was as follows: 5 -very good, $4=$ good, $3=$ undecided, $2=$ fairly decent and $1=$ not at all. Consumers who are familiar with flour-based items served as judges. The tests were carried out in a well-lit environment that was specifically constructed for sensory examination. Between evaluations, the judges were given water to drink to rinse their mouths.

\section{Data Analysis}

ANOVA was used to statistically examine the study's data. The means were separated and the significance level was set at $\mathrm{P}<0.05$.

\section{RESULTS AND DISCUSSION}

\section{Composition of wheat flour pizza, and composite pizza varieties}

The moisture, ash, fat, protein, and total carbohydrate contents of wheat flour pizza and its variations were measured, and the results are reported in Table 2. The moisture value of the $100 \%$ wheat flour pizza was lower $(12.59 \%)$ than the composite pizza variations $(12.64,12.71,12.75$ and $12.83 \%$ respectively). There was a significant difference in moisture $(\mathrm{P}<0.05)$ between the control sample $(\mathrm{MK} 0)$ and the composite samples $(\mathrm{MK} 1$, MK2, MK3 and MK4). When the proportions of cowpea and maize flour were increased, the moisture content of the composite pizza increased. The moisture content of the control pizza was lower than the $14 \%$ specified by the Codex Alimentarius. Low moisture content improves the shelf life of food by inhibiting the growth of microorganisms. It also lowers the likelihood of physical and chemical interactions that lead to degradation and lower flour quality (Aguilera et al., 1995; Van Hal, 2000). All of the pizza samples varied significantly $(\mathrm{p}<0.05)$ in terms of ash and crude fiber content. The ash concentration of the composite pizza sample (MK2) was higher (2.16\%) than that of the control (MK0), which was 1.87\%. Sample MK4 (60\% wheat flour, $25 \%$ maize flour, and $15 \%$ cowpea flour) had the highest ash concentration, while the control sample had the lowest fiber content $(0.77 \%)$. Between the composite pizza samples and the control, statistical results revealed a significant difference $(\mathrm{P}<0.05)$. It was discovered that as the composite flour content was increased, the ash and fiber content increased as well. Although composite flour pizza samples have higher ash and crude fiber content; this could be due to the influence of cowpea and maize flour on the mineral content of the composite blend (Chinma et al., 2012). As a result, incorporating these raw materials into the food product may increase the quantity of mineral intake in the food product (Oyetoro et al., 2007) and hence, provide significant dietary levels. Wheat flour contains less crude fiber than cowpea and maize flour (Chinma et al., 2012; Christine et al., 2012). The amount of crude fiber found in pizzas prepared with wheat, cowpea, and maize composite flour reflected this. The crude fiber levels in all of the pizza samples were less than $\leq$ $6 \mathrm{~g} / 100 \mathrm{~g}$ which is the recommended threshold (FAO, 1994).

Except for fat level, pizza made from wheat, cowpea, and yellow maize composite flour samples (MK1, MK2, MK3, and MK4) has higher protein and carbohydrate contents than pizza made entirely with wheat flour (sample MK0). The protein level ranged from 12.14 to $12.80 \%$, with the pizza sample comprised of $70 \%$ wheat flour, $18 \%$ maize flour, and $12 \%$ cowpea flour having the greatest protein content $(12.92 \%)$ and the control sample (100\% wheat flour) having the lowest (12.14\%). The carbohydrate content of all the pizzas produced ranged from 53.24 to $63.44 \%$. Sample MK4 (60 \% wheat flour, $25 \%$ maize flour, and $15 \%$ cowpea flour) had the highest carbohydrate content (63.44\%), while the control sample MK0 (100\% wheat flour) had the lowest (53.24\%). It was discovered that increasing the the cowpea and maize flour blends resulted in a significant difference $(\mathrm{p}<0.05)$ in the extent of protein and carbohydrate content between pizza made entirely of wheat flour and pizza made with wheat, cowpea, and maize composite flour. Yellow maize and cowpea contain high amount of protein and carbohydrate and that, addition of these local raw materials to wheat flour increased the protein and carbohydrate content (Hui, 1996). 
Table 2: Proximate compositions of wheat flour and wheat, maize and cowpea composite pizza

\begin{tabular}{lllllll}
\hline Samples & Moisture $(\%)$ & Ash $(\%)$ & Fat $(\%)$ & Fibre $(\%)$ & Protein $(\%)$ & CHO $(\%)$ \\
\hline MK0 & $12.59 \mathrm{e}$ & $1.87 \mathrm{e}$ & $1.48 \mathrm{e}$ & $0.77 \mathrm{e}$ & $12.14 \mathrm{e}$ & $53.24 \mathrm{a}$ \\
MK1 & $12.64^{\mathrm{d}}$ & $1.95^{\mathrm{d}}$ & $1.42^{\mathrm{d}}$ & $1.63^{\mathrm{d}}$ & $12.72^{\mathrm{d}}$ & $55.72^{\mathrm{e}}$ \\
MK2 & $12.71^{\mathrm{c}}$ & $2.16^{\mathrm{c}}$ & $1.26^{\mathrm{c}}$ & $2.46^{\mathrm{c}}$ & $12.41^{\mathrm{c}}$ & $58.49^{\mathrm{d}}$ \\
MK3 & $12.75^{\mathrm{b}}$ & $2.31^{\mathrm{b}}$ & $1.30^{\mathrm{b}}$ & $3.34^{\mathrm{b}}$ & $12.92^{\mathrm{b}}$ & $60.66^{\mathrm{c}}$ \\
MK4 & $12.83^{\mathrm{a}}$ & $1.56^{\mathrm{a}}$ & $1.22^{\mathrm{a}}$ & $4.30^{\mathrm{a}}$ & $12.80^{\mathrm{a}}$ & $63.44^{\mathrm{b}}$ \\
\hline
\end{tabular}

Values represent means and standard deviation replicate readings for various parameters. Values in the same column with different superscripts are significantly different ( $\mathrm{p}>0.05)$. MK0 (100\% wheat flour, $0 \%$ maize flour and $0 \%$ cowpea flour), MK1 (90\% wheat flour, 6\% maize flour and 4\% cowpea flour), MK3 (80\% wheat flour, $13 \%$ maize flour and 7\% cowpea flour), MK4 (70\% wheat flour, $18 \%$ maize flour and 12\% cowpea flour) and MK5 (60\% wheat flour, $25 \%$ maize flour and $15 \%$ cowpea flour).

\section{Sensory attributes of wheat flour and wheat, maize and cowpea composite pizza}

Table 3 presents the sensory attributes of wheat flour and wheat, maize and cowpea composite pizza samples produced. At room temperature, the sensory qualities of all pizza samples were assessed. Pizza samples were evaluated using a hedonic scale rating. Aroma, taste, colour, texture, and general acceptance were among the criteria chosen. There was a significant difference $(\mathrm{P}<0.05)$ in the results. The composite pizza sample MK2 $(80 \%$ wheat flour, $13 \%$ maize flour, and $7 \%$ cowpea flour) had the highest mean score $(4.80 \%)$ for aroma, followed by the composite sample MK1 (90\% wheat flour, $6 \%$ maize flour, and $4 \%$ cowpea flour) with $4.70 \%$, and sample MK4 (60\% wheat flour, $25 \%$ maize flour and $15 \%$ cowpea flour) with the lowest mean score $(3.42 \%)$. The control pizza sample (100\% wheat flour) was ranked third highest, with a mean score of $4.30 \%$. It is clear that the augmented samples are acceptable in terms of all of the metrics tested. The major factor that determines whether a product is loved or hated is its flavour (Abu-Salem and Abou-Arab, 2011). Taste and bouquet are two functions of flavour, which is a collection of sensations (Iwe, 2002). Regarding the taste, texture, aroma, and overall acceptability, the replacement pizza samples substantially varied $(\mathrm{P}<0.05)$ from themselves and the control (sample MK0). Sample MK2 has the greatest aroma value (4.70\%), followed by MK1 (4.54\%) and MK0 (control) $(4.20 \%)$. The pizza MK2 (80\% wheat flour, 13\% maize flour, and 7\% cowpea flour) with a value of $4.85 \%$ was the most popular, followed by sample MK1 (90\% wheat flour, $6 \%$ maize flour, and $4 \%$ cowpea flour) with a value of $4.80 \%$, which was higher than the control sample MKO (100\% wheat flour). All pizza samples improved their texture from 2.90 to $4.50 \%$, with sample MK2 obtaining the highest mean score (4.6\%) compared to control sample MK0's 4.30\%. Overall acceptability revealed that the composite pizza sample prepared with $80 \%$ wheat flour, $13 \%$ maize flour, and $7 \%$ cowpea flour was the most chosen.

Table 3: Sensory attributes of wheat flour and wheat, maize and cowpea composite pizza

\begin{tabular}{|c|c|c|c|c|c|c|}
\hline Samples & Aroma/flavour & Taste & Texture & Colour & General & Acceptability \\
\hline MKO & 4.20 & 3.80 & 4.00 & 4.30 & & 4.70 \\
\hline MK1 & 4.54 & 4.30 & 4.50 & 4.70 & & 4.80 \\
\hline MK2 & 4.70 & 4.78 & 4.60 & 4.80 & & 4.85 \\
\hline MK3 & 3.60 & 2.84 & 3.40 & 4.10 & & 3.75 \\
\hline MK4 & 3.00 & 2.10 & 2.90 & 3.42 & & 3.40 \\
\hline
\end{tabular}

Values represent means and standard deviation replicate readings for various parameters. Values in the same column with different superscripts are significantly different $(\mathrm{p}>0.05)$. MKO (100\% wheat flour, $0 \%$ maize flour and $0 \%$ cowpea flour), MK1 (90\% wheat flour, 6\% maize flour and 4\% cowpea flour), MK2 (80\% wheat flour, $13 \%$ maize flour and 7\% cowpea flour), MK3 (70\% wheat flour, 18\% maize flour and 12\% cowpea flour) and MK4 (60\% wheat flour, $25 \%$ maize flour and $15 \%$ cowpea flour).

\section{CONCLUSION}

The study concluded that is possible to make acceptable pizza by substituting cowpea flour and maize flour for wheat flour. The addition of cowpea and maize aided the pizza's firm texture and nutritional characteristics. The 
findings demonstrate that the full potential of cowpeas and maize as components in the production of novel and nutritionally enhanced foods has yet to be realised. Consumer tastes for sustainable plant-based proteins are shifting, potentially extending the use of cowpeas and maize. Pizza sample prepared using 80:13:7\% of wheat, maize, and cowpea blended flour was accepted.

\section{REFERENCES}

1. Abu-Salem, F. M., and Abou-Arab, E. A. (2011). Physico-chemical properties of tempeh produced from chickpea seeds. Journal of American science, 7(7), 107-118

2. Ade-Omowaye, B.I.O., Akinwande, B.A., Bolarinwa I.F. and Adebiyi, A.O. (2008). Evaluation of tigernut (Cyperus esculentus) wheat composite flour and bread. Afr. J. Food Sci., 2: 87-91.

3. Aguilera, J. M., Del Valle, J. M., \& Karel, M. (1995). Caking phenomenon in amorphous food powders. Trends in Food Science and Technology, 6, 149-155

4. Ammar, M.S., Hegazy A.E. and Bedei, S.H. (2009). Using of Taro flour as partial substitute of wheat flour in Bread making. World J. Dairy Food Sci., 4: 94-99.

5. Andrea F. and Aniello C. (2003). Numerical stimulation of the rheological behavior of pizza dough Agricultural Engineering Department. University of Naples Debrecen, Hungary

6. AOAC (2005). Official methods of analysis 18th ed. Arlington, V.A Association of Official Analytical Chemist PP. 806842.

7. AOAC (1990). Association of Official Agricultural Chemists, Official Method of Analysis. 977.20. USA Brink, M., \& Belay, G. (2006). Plant resources of tropical Africa: Cereals and pulses. PROTA Foundation/Blackhuys Publishers/CTA

8. Chinma C.E, Igbabul B.D. and Omotayo O.O. (2012). Quality Characteristics of Cookies Prepared from Unripe Plantain and Defatted Sesame Flour Blends. American Journal of Food Technology; 7:398408.DOI:10.3923/ajft.2012.398.408URL:http://scialert.net/abstract/?doi=ajft.2012.398.408

9. Christine E, Christopher E, and Godwin I. (2012). Nutritional and organoleptic properties of wheat and sesame composite flour baked foods. Journal of food research.; 1(3): URL: http://dx.doi.org/10.5539/jfr.v1n3p84. doi:10.5539/ jfr.vln3p84.

10. Englyst J. (1997). Englyst Enzymatic Gravimetric Method of Total Dietary Fibre Determination. J. Food. Sci. and Agric., 9: $78-85$

11. Enwere, N.J. (1998). Foods of Plant Origin. Afro - Obis Publications Ltd, Nsukka. Pp. $40-48$

12. Enwere, N.J. and Ebiogwu, V.N. (1993). Effect of processing conditions on the quality of the weaning food prepared from cowpea-maize flours. Proceedings of the Nigerian Institute of Food Science and Technology; Pp. $22-23$

13. FAO. (1994). Production Year Book, Food and Agricultural Organisation of the United Nations, Rome.

14. Hui Y.H. (1996). Bailey's Industrial oil and fat products. 5th edn. Wiley Inter-Science Publishers, London.

15. Iwe M.O., (2002). Handbook of sensory methods and analysis. PROJOINT Communications Services Ltd, Enugu, pp. 70-72

16. Kent, N.L. (1984). Technology of cereals: An introduction for Students of Food Science and Agriculture. Third edition. Pergamon Press, Oxford.

17. Khan R. (2005). Effect of soy-flour supplementation on mineral and phytate contents of unleavened flat bread (chapattis.) J. of Nutrition Bulletin 3: 322-168.

18. Lehman T., (1997). Guide to pizza crust production. AIB Technical Bulletin 1(2)

19. Ngoddy, P.O., Enwere, N.J. and Onuorah, V.I. (1986). Cowpea flour in akara and moin-moin preparations. Tropical Science; $26: 101-119$

20. Nnam, N.M. (2002). Evaluation of complementary food based on maize, groundnut, pawpaw and mango flour blends. Nigerian Journal of Nutritional Sciences $22 \& 23,8-18$.

21. Odebode, S.O., Egeonu N. and. Akoroda, M.O. (2008). Promotion of sweet potato for the food industry in Nigeria. Bulgarian J. Agric. Sci., 14: 300-308

22. Okaka, J.C. (1997). Traditional Processing of Grain Legumes In: Cereals and Legumes Storage and Processing Technology. Data and Microsystems Publishers Ltd., Enugu. Pp. $34-50$

23. Okaka J.C. and Isieh M.I. (1990). Development and quality evaluation of cowpea wheat biscuit. Nigerian.Food Journal :56-62

24. Okaka, J. C., \& Potter, N. N. (1979). Sensory, nutritional and storage properties of cowpea powders processed to reduce beany flavor. Journal of Food Science, 44, 1539-1542. https://doi.org/10.1111/j. 1365-2621.1979.tb06482.x

25. Onweluzo J.C., Onuoha K.C. and Obanu Z.A. (1995). A comparative study of some functional properties of Afzelia African and Glycine max flours. Food Chemistry, 54:55-59.

26. Onyemaobi, G.A., Ihekoronye, C.N. \& Okoro, C.I. (2005). Nutritional basis for meal preparation and service. Owerri, Edna-Ben Publishers.

27. Redl A., Guilbert S., Morel M.H. (2003). Heat and shear mediated polymerization of plasticized wheat gluten protein upon mixing. J Cereal Sci 38:105-114

28. Rooney, L.W. \& Serna-Saldvar, S.N., (2000). Sorghum. Handbook of FAO, 2011 
29. Samapundo S., De Meulenaer, B. Osei-Nimoh, D. Lamboni, Y.B. Debevere J.M. and Devlieghere, F. (2007). Can phenolic compounds be used for the protection of corn from fungal invasion and mycotoxin contamination during storage Food Microbiology 24, 465-473

30. Shittu, S. T., Oyeyemi, W. A., Okewumi, T. A. and Salman, T. M. (2013). Role of oxidative stress in therapeutic administration of artesunate on sperm quality and testosterone level in male albino rats African Journal of Biotechnology Vol. 12 (1), pp. 70-73.

31. Shittu T.A., Dixon A., Awonorin S.O, Sanni L.O, and Maziyadixon B. (2008). Bread from composite cassava genotype and nitrogen fertilizer on bread quality. Food Res. Int., 41: 568-578.

32. USDA (2021). Food Data Central. https://fdc.nal.usda.gov/ (accessed June 11, 2021)

33. Van Hal M. (2000). Quality of sweet potato flour during processing and storage. Food Rev. Inter. 16: 1-37. 